\title{
A EVASÃO NO SISTEMA UNIVERSIDADE ABERTA DO BRASIL: UMA ANÁLISE DAS JUSTIFICATIVAS DAS INSTITUIÇÕES INTEGRANTES
}

\section{Dropout in Brazil's Open University System: an analysis of the members institutions' justifications}

\section{La evasión en el Sistema Universidad Abierta de Brasil: un análisis de las justificaciones de las instituciones miembros}

\begin{abstract}
Danielle Xabregas Pamplona Nogueira*
Marcello Ferreira ${ }^{* *}$

Luiz Alberto Rocha de Lira ${ }^{* * *}$

Resumo

Este artigo trata da evasão em cursos à distância. Tem como objetivo analisar as justificativas acadêmicas apresentadas por instituições de educação superior (IES) a propósito da evasão discente nos cursos ofertados no âmbito do Sistema Universidade Aberta do Brasil (UAB). A pesquisa envolveu a realização de análise de conteúdo nos textos das 77 justificativas apresentadas por IES do Sistema UAB à Coordenação de Aperfeiçoamento de Nível Superior (Capes), relativamente à evasão em cursos de graduação e de pós-graduação lato sensu. Os resultados apontaram que, na maioria dos casos, do ponto de vista dos alunos, a falta de internet e a pouca habilidade para manejar as ferramentas tecnológicas têm sido os principais causadores de evasão. Quanto às IES, as principais alegações se relacionam à precariedade de profissionais, principalmente os tutores, além de fatores relativos à equipe multidisciplinar, como o desenvolvimento de materiais didáticos e videoaulas. Outro fator considerado como de principal correlação ao fenômeno foi a ausência ou falta de qualidade na infraestrutura.
\end{abstract}

PALAVRAS-CHAVE: Evasão. Educação à Distância. Sistema Universidade Aberta do Brasil.

\section{Abstract}

This article deals with dropout in distance learning. It aims to analyze the academic justifications presented by higher education institutions (HEIs) regarding student dropout in courses offered within the scope of the Open University System of Brazil (UAB). The research involved conducting content analysis in the texts of the 77 justifications presented by IESs of the UAB System to the Coordination of Superior Level Staff Improvement (Capes), regarding evasion in undergraduate and graduate courses lato sensu. The results showed that, in most cases, from the students' point of view, the lack of internet and the lack of ability to handle technological tools have been the main causes of evasion. As for HEIs, the main allegations are related to the precariousness of professionals, especially tutors, in addition to factors related to the multidisciplinary team, such as the development of teaching materials and video classes. Another factor considered to be the main correlation to the phenomenon was the absence or lack of quality in the infrastructure.

KEYWORDS: Dropout. Distance Education. Open University System of Brazil.

\footnotetext{
* Doutora em Educação. Docente vinculada à Faculdade de Educação - Universidade de Brasília (UnB). Email: daniellen@unb.br. Orcid: https://orcid.org/0000-0001-8500-0402

** Doutor em Educação em Ciências. Docente vinculado ao Instituto de Física - Universidade de Brasília (UnB). E-mail: marcellof@ unb.br. Orcid: https://orcid.org/0000-0003-4945-3169

*** Doutor em Educação. Coordenador-Geral de Programas e Cursos em EaD - DED/Capes. E-mail: luiz.lira@capes.gov.br. Orcid: https://orcid.org/0000-0001-8719-700X
} 


\section{Resumen}

Este artículo trata sobre la evasión en cursos a distancia. Su objetivo es analizar las justificaciones académicas presentadas por las instituciones de educación superior (IES) con respecto al abandono de los estudiantes en los cursos ofrecidos dentro del ámbito del Sistema Universidad Abierta de Brasil (UAB). La investigación incluyó la realización de análisis de contenido en los textos de las 77 justificaciones presentadas por IES del Sistema UAB a la Coordinación para el Mejoramiento de la Educación Superior (Capes), con respecto a la evasión en los cursos de pregrado y posgrado lato sensu. Los resultados mostraron que, en la mayoría de los casos, desde el punto de vista de los estudiantes, la falta de internet y la falta de capacidad para manejar las herramientas tecnológicas han sido las principales causas del abandono. En cuanto a las IES, las principales denuncias están relacionadas con la precariedad de los profesionales, principalmente tutores, además de factores relacionados con el equipo multidisciplinario, como el desarrollo de materiales didácticos y clases de video. Otro factor considerado como la principal correlación con el fenómeno fue la ausencia o falta de calidad en la infraestructura.

PALABRAS CLAVE: Evasión. Educación a Distancia. Sistema Universidad Abierta de Brasil.

\section{INTRODUÇÃO}

A evasão na educação superior brasileira tem sido um dos desafios frente às políticas de democratização do acesso a esse nível educacional. Dados obtidos em estudo desenvolvido por Silva Filho et al. (2007) demonstraram que a tendência de evasão, especialmente na modalidade a distância, é crescente nos diversos tipos de curso.

De acordo com Sousa e Maciel (2016), apesar da evidenciação de altas taxas de evasão na educação superior brasileiras, os estudos realizados acerca da temática são pouco expressivos, especialmente quanto à modalidade a distância. Por isso, as autoras afirmam a urgência para que as dimensões da evasão (evasão do curso, da instituição ou do sistema de ensino) sejam investigadas, para que seja possível identificar as taxas de diplomação, retenção e evasão dos cursos de graduação oferecidos nas diferentes IES. Além disso, é importante considerar as especificidades das instituições, dos cursos e das regiões do país, posto que essas IES possuem características peculiares: sociais, econômicas, culturais, acadêmicas e pessoais.

A fim de compreender como se expressa o fenômeno da evasão no âmbito dos cursos da Universidade Aberta do Brasil (UAB), a Coordenação de Aperfeiçoamento de Nível Superior (CAPES) solicitou às Instituições de Ensino Superior (IES) que apresentassem justificativas sobre a evasão discente. Tais justificativas foram apresentadas, em documentos que deveriam ser limitados a uma lauda, em resposta à solicitação feita pela Capes por meio do Ofício Circular no 30/2018-CGPC/DED/CAPES, de 4 de dezembro de 2018 (CAPES, 2018).

$\mathrm{Na}$ formulação da demanda, a Capes consignou que caberia justificativa, até 21/1/2019, a "indicadores de formação abaixo de $50 \%$ em ofertas com data de término real em 31.12.2016", considerando cursos de graduação e de pós-graduação lato sensu. À comunicação, foi anexada planilha que indicava tais indicadores, por IES e por curso, considerando dados do Sistema de Informação da UAB (SisUAB) aferidos em 27/11/2018.

A consulta cabe mencionar, envolveu a oferta de 825.031 vagas em cursos de extensão, aperfeiçoamento, especialização (lato sensu), tecnólogo, bacharelado, licenciatura e sequencial de complemento de estudos, por 109 instituições públicas de 
ensino superior no período de 2005 a 2020 (portanto, ofertas concluídas e em andamento). A evasão média do Sistema UAB, nessa estratificação, é de 44,51\% (367.201).

Por fim, a Capes alertou às IES do Sistema UAB "sobre a preocupação desta $D E D / C G P C$, acerca de cursos que continuam sendo ofertados e reofertados $e$, recorrentemente apresentando baixos índices de formação, portanto alertamos sobre a necessidade de um acompanhamento acadêmico periódico que possa evidenciar melhorias contínuas ao sistema UAB".

Foi a esta orientação, portanto, a que tiveram acesso as IES do Sistema UAB. 77 (setenta e sete) delas atenderam à demanda, quais sejam: CEFET; Fiocruz; FURG; IFAM; IFCE; IFES; IFMA; IFMT; IFPB; IFPE; IFRN; IFRR; IFSC; IFSUL; UDESC; UECE; UEG; UEL; UEM; UEMA; UEMG; UEMS; UENF; UEPA; UEPB; UEPG; UERJ; UERN; UESB; UESC; UESPI; UFABC; UFAM; UFBA; UFC; UFERSA; UFES; UFF; UFG; UFGD; UFGRS; UFJF; UFLA; UFMA; UFMG; UFMT UFOP; UFPA; UFPE; UFPEL; UFPI; UFPR; UFRJ; UFRN; UFRPE; UFRRJ; UFSCAR; UFSJ; UFSM; UFT; UFU; UFV; UFVJM; UNB; UNEB; UNEMAT; Unicentro; UNIFAL; UNIFEI; UNIFESP; Unilab; Unimontes; UNIR; Unirio; Unitins; UNIVASF; e UTFPR.

Neste artigo, apresentamos uma análise das justificativas acadêmicas apresentadas por IES a propósito da evasão discente nos cursos ofertados no âmbito do Sistema Universidade Aberta do Brasil (UAB).

\section{Fatores intervenientes na evasão em cursos à distância: breve revisão de literatura}

Estudos como de Tinto (1975) propõem modelos teóricos para explicar o processo de evasão. Para o autor, primeiro são examinadas as características dos próprios indivíduos que parecem estar relacionadas à sua persistência na faculdade. No segundo aspecto, é analisada a interação desse indivíduo com ambiente acadêmico. Já o terceiro aspecto diz respeito às características das IES que influenciam o processo de abandono por parte do estudante. Tal como Tinto (1975), Kember (1995) definiu que o abandono de curso é causado por dois grandes fracassos: a integração malsucedida na vida social da instituição e/ou a compatibilidade insatisfatória às demandas acadêmicas.

Lee e Choi (2011), ao identificarem 69 fatores que influenciam a evasão, os classificaram em três categorias principais: (a) fatores do estudante, (b) fatores do curso/programa, e (c) fatores ambientais. Os fatores relacionados ao estudante foram as variáveis mais citadas, compreendendo quatro subcategorias: experiências acadêmicas anteriores, experiências relevantes, competências relevantes e atributos psicológicos. Os fatores referentes ao curso/programa são: design, suportes institucionais e interações. Já os fatores ambientais incluem compromissos de trabalho, várias responsabilidades familiares e sociais e apoio insuficiente da família, amigos ou colegas.

Na mesma direção, Ramos, Bicalho e Sousa (2014) realizaram uma pesquisa de base documental, com base em revisão da literatura internacional, acerca dos fatores de evasão e de persistência em cursos superiores a distância. Nela, os autores analisam a evasão no ensino superior on-line na perspectiva de um fenômeno multidimensional. Segundo eles, a evasão compreende fatores como estudante, professor, conteúdos e as tecnologias usadas no ambiente virtual; dos relacionados ao projeto pedagógico, desenho do curso, tipos de interações e padrões de participação nos cursos on-line; e as questões relacionadas à infraestrutura e às políticas institucionais. Assim, constituíram um panorama 
dos estudos a respeito da evasão e da persistência organizados por níveis institucionais de responsabilização. São eles:

a) nível micro: trata das questões relacionadas à interação entre os envolvidos no processo de ensino-aprendizagem. Os autores recomendam a valorização da qualidade dessas interações e as construções do conhecimento. Para isso, orientam que docentes (professores e/ou tutores) mantenham o foco nos objetivos da aprendizagem, de forma proativa, fornecendo feedback imediato aos estudantes para diminuir as distâncias; desenho;

b) nível meso: diz respeito às dimensões do curso, ao seu planejamento e ao

c) nível macro: refere-se a ações de institucionalização da $\mathrm{EaD}$, formulação de planos e de políticas de retenção, financiamento ao estudante e apoio à aprendizagem que refletem nos níveis meso e micro.

Discutindo a multidimensionalidade do fenômeno da evasão, Sousa e Maciel (2016) concluem que a evasão se materializa devido ao conjunto de fatores que envolvem a relação sociocultural, as IES, o curso e o estudante. Por isso, consideram que evasão não pode mais ser justificada somente pelas opções pessoais dos estudantes, posto que muitos elementos que determinam essa evasão são, também, confundidos com as dificuldades específicas da modalidade a distância. As autoras ainda destacam a necessidade de políticas de acompanhamento dos estudantes nessa modalidade, especialmente nos primeiros anos dos cursos, momento em que as pesquisas revelam maior percentual de abandono.

Reis e Veloso (2016) indicam seis elementos que interferem na permanência do estudante nas universidades: o ambiente acadêmico, o estudante trabalhador, o capital cultural, a escolha do curso, situação financeira do estudante e as ações assistenciais e qualificadoras. As autoras ressaltam que a modificação do perfil de ingressantes nas universidades públicas (que, com as políticas de expansão, passaram a integrar maior diversidade cultural e socioeconômica) impõe a intensificação de investimentos em políticas de apoio à permanência, ressalvada a qualidade do ensino.

Nesse sentido, admite-se que a permanência do estudante em cursos a distância deve considerar as reais condições dele (escolares, culturais, econômicas, sociais), sobre as quais as políticas institucionais devem ser pensadas/planejadas para apoiá-lo, pois características individuais desfavoráveis podem ser reforçadas por dificuldades ou inadequações institucionais.

\section{Metodologia aplicada à análise}

Esta pesquisa contempla os conteúdos textuais (corpus) das 77 justificativas apresentadas por IES do Sistema UAB à Capes, a propósito da evasão em cursos de graduação e de pós-graduação lato sensu até 31/12/2016. A pormenorização do material subsidia-se em procedimentos de Análise de Conteúdo (AC), bem como no uso do software Iramuteq.

\section{Análise de conteúdo}

A presente pesquisa utiliza-se da análise de conteúdo, a qual compreende

um conjunto de técnicas de análise das comunicações visando obter, por procedimentos sistemáticos e objetivos de descrição do conteúdo das mensagens, 
indicadores (quantitativos ou não) que permitam a inferência de conhecimentos relativos às condições de produção/recepção (variáveis inferidas) destas mensagens (BARDIN, 2011, p. 48).

É uma metodologia utilizada para descrever e interpretar o conteúdo de toda classe de documentos e textos. Essa análise conduz a descrições sistemáticas, que auxiliam a reinterpretar as mensagens e a atingir uma compreensão de seus significados em um nível que vai além de uma leitura comum (MORAES, 1999). Visa à organização e à sistematização de unidades textuais para a evidenciação de núcleos de sentido, a exemplo de temas, conceitos e significados.

A análise de conteúdo se apoia, dentre outros, em procedimentos da análise lexical, que se caracteriza por um conjunto de procedimentos destinados à descrição de sequências textuais como subsídio à evidenciação de conteúdos e à interpretação de seus significados.

Segundo Franco (2005), a análise de conteúdo consiste em um processo que inicia com a descrição, etapa que enumera as características dos dados e as resume após um tratamento inicial, e vai até a interpretação, que é a significação concedida às características. Como processo intermediário, a inferência é que vai permitir a passagem da descrição à interpretação.

Tendo sido conhecido o material analisado, foram definidas as unidades de análise. Tomando como referência a implementação mencionada, as unidades de análise constituídas se dividiram em unidades de registro e unidades de contexto. Franco (2005) define unidade de registro como a menor parte do conteúdo, podendo ser de diferentes tipos; porém, mesmo estando inter-relacionadas e em complementaridade, cada uma delas deve estar adaptada à investigação. A unidade de contexto, por sua vez, consiste na parte mais ampla do conteúdo a ser analisado, pois imprime significado às unidades de análise.

A análise de contexto deve ser considerada e tratada como a unidade básica para a compreensão da codificação da unidade de registro e corresponde ao segmento da mensagem, cujas dimensões são excelentes para a compreensão do significado exato da unidade de registro (FRANCO, 2005, p. 44).

Convém esclarecer que, segundo Franco (2005), a realização de comparações contextuais implicou o entendimento de diferenças e semelhanças de significados atribuídos pelos sujeitos investigados. Nesta perspectiva, as unidades de contexto foram trabalhadas para que fosse possível esclarecer as contingências contextuais em que as informações foram produzidas, no caso, as IES.

Em seguida à definição das unidades de análise, foi realizada a etapa de préanálise, que consistiu na organização da análise e na definição das categorias. $\mathrm{Na}$ organização da análise foi feita a leitura flutuante ${ }^{l}$; a formulação de hipóteses e/ou dos objetivos; e a elaboração de indicadores para a interpretação final. Nessa etapa, os dados obtidos foram agrupados e classificados de acordo com o conteúdo apresentado. Da classificação proposta, foram constituídos indicadores, que auxiliaram na posterior criação de categorias.

Quanto à categorização, esta compreende "uma operação de classificação dos elementos constitutivos de um conjunto por diferenciação, seguida de um reagrupamento

\footnotetext{
1 A leitura flutuante "consiste em estabelecer contatos com os documentos a serem analisados e conhecer os textos e as mensagens neles contidas, deixando-se invadir por impressões, emoções, conhecimentos e expectativas" (FRANCO, 2005, p. 48).
} 
baseado em analogias, a partir de critérios definidos" (FRANCO, 2005, p. 57). Desse modo, a categorização foi obtida a posteriori, considerando os indicadores definidos anteriormente e orientada pela incidência de temas e de conceitos que foram surgindo nos documentos analisados.

Após o devido tratamento dos resultados obtidos, a interpretação deles compreendeu a fase final de análise. Dessa forma, essa fase foi orientada pelos conteúdos manifestos do aprofundamento da análise dos documentos e de dados resultantes do processo de produção de informações, subsidiados pelo referencial teórico adotado.

A análise de conteúdo foi instrumentalizada pelo software Iramuteq - Interface de $R$ pour les Analyses Multidimensionnelles de Textes et de Questionnaires.

A CHD, ou Método Reinert, utiliza a correlação das palavras em segmentos no corpus textual, comparando-as com a lista de formas reduzidas e com o dicionário de vocábulos, que apresenta como resultado o esquema hierárquico de classes. Com base nelas, pode-se inferir as ideias contidas no corpus textual. As classes indicam os vocabulários presentes no corpus do texto e a porcentagem de abrangência dele. Considera-se na análise de conteúdo, o corpus da pesquisa ou o corpus da análise como o conjunto de textos selecionados pelo pesquisador, o qual é recortado em segmentos de texto (ST) para que se observe a distribuição das palavras plenas (que possuem semântica) nesses segmentos. O vocabulário é formado por todas as formas de um texto (substantivos, verbos, adjetivos etc.), e o número de ocorrências (palavras, formas ou vocábulos) contidas em um texto é seu comprimento. Quando o conjunto de textos versa a respeito do mesmo tema, o método adequado de análise é a CHD, uma das métricas de análise de conteúdo mais importante que o Iramuteq permite realizar (SACERDOTE, 2018). Desse modo, neste relatório utilizou-se o método $\mathrm{CHD}$, por julgar ser adequado à presente investigação.

\section{Resultados}

\section{Estatísticas textuais}

O corpus geral foi constituído por 77 textos (UCI) - referentes às 77 IES distintas identificadas -, separados em 1.801 STs, com aproveitamento de 1.675 STs (93\%). Emergiram 64.576 ocorrências, sendo 6.554 palavras distintas e 3.048 com uma única ocorrência (hapax).

O corpus analisado foi categorizado em cinco classes: Classe 1, com 291 STs (17,37\%); Classe 2, com 365 STs $(21,79 \%)$; Classe 3, com 376 STs $(22,45 \%)$; Classe 4, com 409 STs $(24,42 \%)$; e Classe 5, com 234 STs $(13,97 \%)$.

Foram utilizados: a lematização - classificação de formas reduzidas de algumas palavras (radicais); e os parâmetros-chaves: substantivos e verbos.

\section{Classificação Hierárquica Descendente - CHD}

Vale ressaltar que essas cinco classes estão divididas em duas ramificações (A e B) do corpus total em análise.

a) O subcorpus A, denominado "Dados do ofício", contém os dados que compõem a correspondência de resposta ao ofício à Capes e contém apenas a Classe 5.

b) O subcorpus B, nomeado "Dados das IES", é composto por duas ramificações: B1, nomeada "cursos e ofertas"; e B2, nomeada "justificativas e causas". 


\section{B1: Cursos e ofertas}

a) B1.1 - cursos, formado pela classe 4, que se refere aos dados dos cursos ofertados pelas IES na modalidade EaD.

b) B1.2 - ofertas, formado pela classe 3, que se refere aos dados das ofertas dos cursos ofertados pelas IES na modalidade EAD e algumas medidas que têm sido adotadas visando a tratar o problema da evasão escolar.

\section{B2: Ações e justificativas}

a) B2.1 - ações ou medidas, formado pela classe 2, que se refere às ações ou medidas que têm sido adotadas para diminuir a evasão escolar;

b) B2.2 - justificativas, formado pela classe 1, que se refere às causas identificadas que impactam na evasão escolar.

Para esta análise, o subcorpus A foi desprezado pois não foi considerado como relevante para o objetivo da pesquisa. Ela representou um percentual de $13,97 \%$ de todo o corpus selecionado para a análise. Além disso, o subcorpus B1 também foi desconsiderado. Desse modo, apenas o subcorpus B2, com as suas subdivisões (B2.1 e B2.2) foi considerado.

O subcorpus B2.1 (ações ou medidas) é formado pela classe $2(21,79 \%$ ) e o subcorpus B2.2 (causas) pela classe $1(17,37 \%)$. Assim, a classe 2 é mais relevante quando comparada à classe 1 , em relação ao corpus total da análise, embora a classe 1 seja aquela que contém as informações que atendem ao problema desta pesquisa.

Destarte, as classes nas quais analisamos neste relatório foram aquelas compostas pelo subcorpus B2 (B2.1 - classe 2; e B2.2 - classe 1).

Para atingir uma melhor visualização das classes, manipulou-se o dendrograma gerado pelo Iramuteq (Figura 1) e criou-se um quadro com a lista das principais palavras das classes 2 e 1 gerada a partir do teste $\mathrm{x}^{2}$ e em seus STs (Quadro 1). Neles emergem as evocações que apresentam vocabulário semelhante entre si.

A seguir estão descritas, operacionalizadas e exemplificadas as classes 2 e 1, emergidas na CHD, como as mais significativas quando comparada ao corpus textual; e referentes ao problema no qual se busca entender.

\section{Classe 2 - ações ou medidas}

Essa classe é a mais relevante e compreende $21,79 \%(f=365$ STs $)$ do corpus total analisado. Ela é constituída por palavras e radicais no intervalo entre $\mathrm{x}^{2}=16,64$ (frequência) e $\mathrm{x}^{2}=258,01$ (tutor). Essa classe é composta pelos vocábulos apresentados no quadro 1, com seus respectivos $\operatorname{STs}(f)$ e $\mathrm{x}^{2}$. Predominaram as evocações das IES UTFPR $\left(29\right.$ STs; $\left.x^{2}=53,97\right)$ e IFSC (35 STs; $\left.x^{2}=25,57\right)$.

$\mathrm{Na}$ análise realizada, verificou-se que as principais ações e/ou medidas que estão sendo adotadas para diminuir os índices de evasão escolar pelas IES dizem respeito principalmente às questões relacionadas com tutores, ao acompanhamento de alunos por eles, as tentativas de contatos telefônicos etc. Entre as palavras que mais ocorreram em um número maior de STs nessa classe estão: tutor (122), professor (99), disciplina (73), atividade (69), coordenação (57), realizar (53) e equipe (47). Quando se observa o x², as 
palavras tutor $(258,01)$, professor $(132,1)$, reunião $(84,39)$, avaliação $(80,47)$, equipe $(76,98)$ e acompanhar $(72,98)$, aparecem com relevância, conforme se observa no quadro 1. Isso denota um esforço da equipe nas ações de resgate e de recuperação dos estudantes, com ênfase no trabalho do tutor.

Dessa maneira, podem ser observados alguns textos com altos scores (soma de $\mathrm{x}^{2}$ de formas marcadas no segmento), portanto, alguns dos mais significativo da classe 2, do conteúdo dos documentos enviados à Capes. Vale ressaltar, que o grifo é gerado pelo próprio software e foi transcrito da mesma maneira para enfatizar quais são, no trecho selecionado, as palavras mais frequentes no corpus textual:

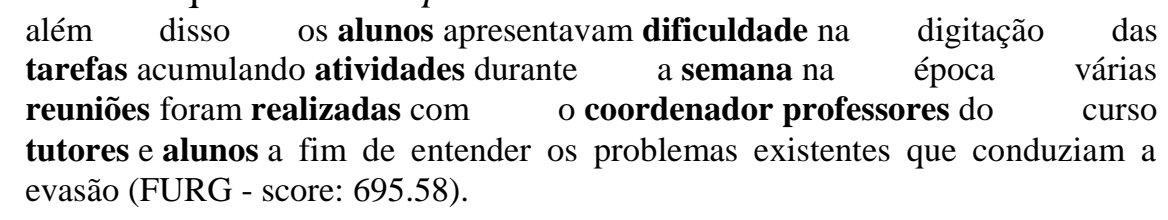

intensificação nas reuniões de coordenadoria para acompanhamentos das execuções dos componentes curriculares bem como orientações as coordenações de polo e tutoria presencial para ações propositivas e quando detectados afastamentos infrequências de estudantes uma ação imediata do tutor presencial junto aos estudantes (IFSUL - score: 677.79).

acompanhar as atividades dos tutores como acesso diário ao ava tempo de resposta ao aluno avaliação das tarefas participação nos nos fóruns contatar os alunos ausentes ao curso através do ava por email telefone como também na própria casa desses (UEMA - score: 671.92).

foram feitas reuniões periódicas com estudantes coordenadores e polos tutores e professores a fim de identificar as dificuldades dos alunos disciplinas que apresentaram alto grau de reprovação foram readequadas e reofertadas diversas vezes (UFV - score: 637.52).

tal acompanhamento inclui procedimentos como resgate e recuperação de estudantes, interação e mediação de tutores, identificação de boas práticas, monitoramento de frequência, e desempenho nas avaliações presença de estudantes no ava plataforma moodle (UNIRIO - score: 630.76).

\section{Classe 1: justificativas}

Apesar de essa classe ter sido menos relevante que a 2, no que diz respeito ao método, quanto ao conteúdo, ela é a mais relevante para os objetivos deste relatório, e compreende $17,37 \%$ ( $f=291 \mathrm{STs}$ ) do corpus total analisado. Ela é constituída por palavras e radicais no intervalo entre $x^{2}=15,32$ (sala) e $x^{2}=100,05$ (internet). Essa classe é composta pelos vocábulos apresentados no quadro 1 , com seus respectivos $\operatorname{STs}(f)$ e $\mathrm{x}^{2}$. Predominaram as evocações das IEs UESC $\left(40\right.$ STs; $\left.x^{2}=28,84\right)$ e UnB $\left(15\right.$ STs; $x^{2}=$ 19,78).

$\mathrm{Na}$ análise realizada, verificou-se que as principais causas identificadas pelas IES que impactam nos índices de evasão escolar dizem respeito principalmente às questões relacionadas com acesso à internet pelos alunos, dificuldades no uso das ferramentas tecnológicas e do AVA, falta de equipamentos e laboratórios e dificuldades particulares. Entre as palavras que mais ocorreram em um número maior de STs nessa classe estão: dificuldade (55), material (41), acesso (41), aprendizagem (34), ambiente (33) e internet (32). Quando se analisa o $\mathrm{x}^{2}$, a palavra internet $(100,5)$ aparece como mais relevante, seguida de material $(98,4)$, acesso $(95,84)$, uso $(93,5)$ e ambiente $(84,9)$, conforme se 
observa no quadro 1. Isso denota que as dificuldades de acesso ao ambiente de aprendizagem e ao material didático foi maximizado pela falta de internet, mais do que pelos problemas pessoais.

Dessa maneira, podem ser observados alguns textos com altos scores (soma de $\mathrm{x}^{2}$ de formas marcadas no segmento), portanto, alguns dos mais significativo da classe 1, do conteúdo dos documentos enviados à Capes, conforme alguns textos selecionados a seguir. o aluno não se sentia preparado para estudar online faltava compreensão da estrutura do ambiente virtual ocorreram dificuldades com acesso à internet nas cidades do interior do mato grosso dificuldade com a administração do tempo seja por excesso de trabalho ou por organização pessoal (UFMT - score: 462.79)

pouca interação do aluno no ambiente virtual de ensino aprendizagem tanto com os colegas como também com os tutores e professores formadores dificuldade de acesso ao computador e internet pelos alunos em suas residências índica alto à época (UEG - score: 449.69)

a modalidade a distância também foi uma novidade para muitos as e as dificuldades com o uso da tecnologia foi uma barreira que muitos não superaram mesmo com as medidas de ambientação adotadas pelos cursos também foram relatados casos em que a falta de acesso a internet em casa era um problema (UFG - score: 442.55)

muito material para ler falta de interesse pelo curso escolhido mudança de emprego ter matrícula em universidade pública e bolsa em universidade particular falta de empenho do aluno nos estudos falta de acesso a internet em casa (UEPG - score: 381.33 ) 
Figura 1 - Dendrograma da CHD

\section{Avaliação dos cursos EAD}

1.675 STs - aproveitamento $93 \%$

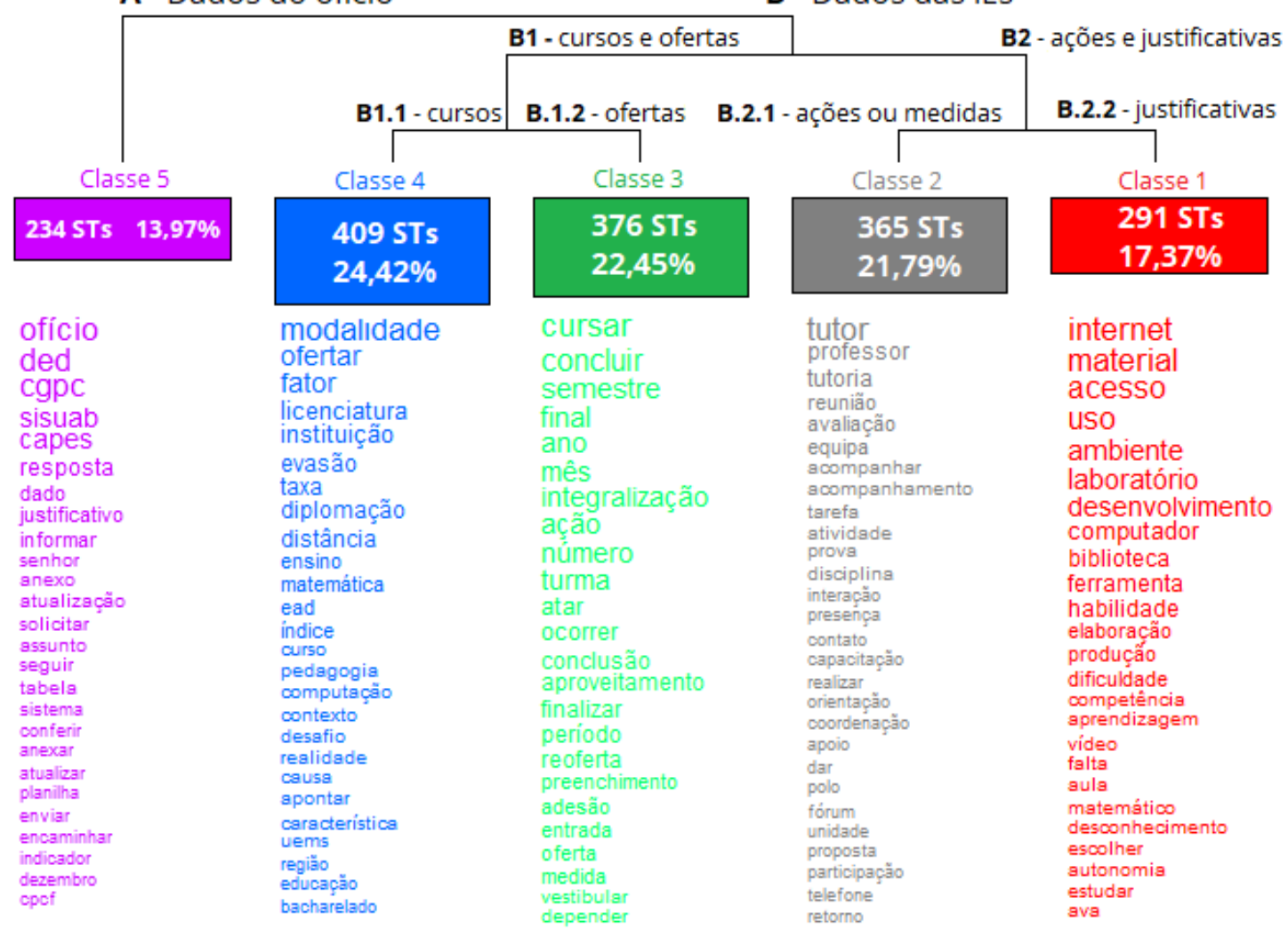

Fonte: Elaboração do autor

Quadro 1 - Classe 2 e classe 1

\begin{tabular}{|l|l|l|l|c|l|}
\hline \multicolumn{3}{|c|}{ Classe 2} & \multicolumn{3}{c|}{ Classe 1} \\
\hline \multicolumn{1}{|c|}{ Forma } & \multicolumn{1}{c|}{$f$} & \multicolumn{1}{c|}{$\mathrm{X}^{2}$} & \multicolumn{1}{c|}{ Forma } & $f$ & $\mathrm{X}^{2}$ \\
\hline Tutor & 122 & 258,01 & Internet & 32 & 100,5 \\
\hline Professor & 99 & 132,1 & Material & 41 & 98,4 \\
\hline Reunião & 26 & 84,39 & Acesso & 41 & 95,84 \\
\hline Avaliação & 43 & 80,47 & Uso & 27 & 93,05 \\
\hline Equipe & 47 & 76,98 & Ambiente & 33 & 84,9 \\
\hline acompanhar & 35 & 72,98 & Laboratório & 17 & 81,68 \\
\hline Tarefa & 18 & 65,3 & Desenvolvimento & 26 & 67,59 \\
\hline Atividade & 69 & 58,73 & Computador & 14 & 67,15 \\
\hline Prova & 18 & 50,99 & Biblioteca & 12 & 57,48 \\
\hline Disciplina & 73 & 48,81 & Ferramenta & 15 & 55,15 \\
\hline Interação & 17 & 43,68 & Habilidade & 14 & 50,52 \\
\hline Presença & 12 & 43,38 & elaboração & 11 & 46,47 \\
\hline Contato & 18 & 37,54 & Produção & 18 & 43,66 \\
\hline Capacitação & 19 & 35,46 & Dificuldade & 55 & 39,03 \\
\hline Realizar & 53 & 34,49 & competência & 9 & 36,97 \\
\hline Orientação & 20 & 33,84 & Aprendizagem & 34 & 36,95 \\
\hline Coordenação & 57 & 32,84 & Vídeo & 11 & 36,83 \\
\hline apoio & 34 & 30,74 & Falta & 31 & 34,57 \\
\hline & & & Aula & 24 & 33,68 \\
\hline
\end{tabular}




\begin{tabular}{|l|l|l|l|l|l|} 
& & & Matemática & 7 & 33,43 \\
\hline & & & Desconhecimento & 7 & 33,43 \\
\hline & & & escolher & 8 & 32,24 \\
\hline & & & Autonomia & 8 & 32,24 \\
\hline & & & estudar & 12 & 30,8 \\
\hline
\end{tabular}

Fonte: Elaboração do autor

\section{Análise dos dados e discussão}

Conforme foi abordado nesta análise, e de acordo com o referencial teórico apresentado, os fatores que impactam na evasão são os descritos no quadro 3. Como foi possível perceber e de maneira resumida, as principais dimensões relacionadas aos fatores que causam a evasão compreendem as questões: particulares dos alunos (características individuais e de interação com o ambiente acadêmico; fatores do estudante; interações no processo ensino-aprendizagem; sociais, econômicas, culturais e pessoais); e aquelas referentes às IES (características institucionais, fatores do curso/programa; dimensões do curso e institucionalização da EaD; e acadêmicas).

Quadro 2 - fatores de evasão

\begin{tabular}{|l|l|}
\hline \multicolumn{1}{|c|}{ Autores } & \multicolumn{1}{c|}{ Fatores que impactam na evasão } \\
\hline \multirow{3}{*}{ Tinto (1975) } & 1) características individuais \\
& 2) interação com o ambiente acadêmico \\
& 3) características da IES \\
\hline \multirow{3}{*}{ Lee; Choi (2011) } & 1) fatores do estudante \\
& 2) fatores do curso/programa \\
& 3) fatores ambientais \\
\hline \multirow{3}{*}{ Ramos; Bicalho; Sousa (2014) } & 1) interações no processo ensino-aprendizagem \\
& 2) dimensões do curso \\
& 3) institucionalização da EAD \\
\hline \multirow{3}{*}{ Souza; Maciel (2016) } & 1) sociais \\
& 2) econômicas \\
& 3) culturais \\
& 4) acadêmicas \\
& 5) pessoais \\
\hline
\end{tabular}

Para identificar as dimensões identificadas, utilizou-se o método CHD que permitiu inferir as ideias contidas no corpus textual por meio das classes que emergiram, identificadas e nomeadas pela relevância dos vocábulos nelas contidos.

Desse modo, ao analisar o corpus textual e os relatórios que o Iramuteq gerou, por classe, e comparando às dimensões identificadas no referencial teórico, elencaram-se as seguintes situações que são indicativas de que influenciam na evasão:

1. Questões particulares dos alunos:

a) problemas de ordem pessoal: saúde, gravidez, falecimento de parentes, doenças familiares;

b) os alunos que são professores da rede pública, alegam excesso de carga horária de trabalho;

c) dificuldades no uso das tecnologias;

d) dificuldades de acesso à internet; 
e) dificuldades de adaptação à EAD: autodisciplina; organização do tempo; das entregas das atividades;

f) dificuldade no uso do AVA e das ferramentas tecnológicas;

g) dificuldades de deslocamento para as atividades presenciais nos polos;

h) conciliação trabalho e estudo;

i) isolamento acadêmico;

j) mais de uma disciplina simultânea;

k) carga horária inadequada: excessiva ou insuficiente.

2. Questões referentes às IES:

a) falta de tutor presencial;

b) valor das bolsas desatualizado há mais de 10 anos;

c) instabilidade de pagamento das bolsas

d) dificuldade de manter a equipe pelo valor da bolsa;

e) mudanças frequentes na equipe;

f) falta de habilitação dos tutores;

g) deficiência na formação de professores;

h) material didático inadequado: denso e linguagem complexa;

i) falta de material didático impresso;

j) dificuldade em gravar videoaulas

k) corte de verbas;

1) não disponibilização do repercurso;

m) greve de funcionários;

n) falta de infraestrutura dos polos: equipamentos tecnológicos;

o) falta de energia elétrica;

p) falta de biblioteca e de laboratórios nos polos.

Não há análise da categoria curso, pois as justificativas das IES não contemplaram tal nível de especificação.

\section{CONSIDERAÇÕES FINAIS}

Conforme abordado, os dados de análise desta análise são oriundos dos relatórios apresentados pelas IES à Capes, relativamente à situação da evasão nos cursos oferecidos por elas oferecidos na modalidade EaD.

Ao longo do tratamento, do processamento, da análise dos dados e dos resultados encontrados, foi possível perceber que os índices de evasão são significativos. Embora as IES estejam adotando ações e medidas para conter a situação de evasão (conforme é possível observar na ramificação B2.1 da CHD apresentado no dendrograma da figura 1), a maioria delas ainda não conseguiram atingir o seu objetivo.

Observou-se que, na maioria dos casos, do ponto de vista dos alunos, a falta de internet e a pouca habilidade para manejar as ferramentas tecnológicas têm sido os principais causadores de evasão.

Do ponto de vista das IES, o problema principal está nos recursos humanos, principalmente os tutores, que parecem ser o centro da EaD: questões de valores e pagamentos de bolsas; rotatividade; desmotivação e deficiência de formação. Também há 
deficiências que dizem respeito à equipe multidisciplinar, envolvendo o desenvolvimento de materiais didáticos e vídeoaulas. Finalmente, outro fator considerado como de principal correlação ao fenômeno foi a ausência ou falta de qualidade na infraestrutura.

\section{REFERÊNCIAS}

BARDIN, L. Análise de conteúdo. São Paulo: Edições 70, 2011.

CAPES. Coordenação de Aperfeiçoamento de Pessoal de Nível Superior. Diretoria de Educação a Distância. Coordenação-Geral de Programas e Cursos em Ensino a Distância. Ofício Circular nº 30/2018-CGPC/DED/CAPES, de 4 de dezembro de 2018.

FRANCO, M. L. P. B. F. Análise de conteúdo. 2. ed. Brasília: Líber Livro, 2005.

LEE, Y.; CHOI, J. A review of online course dropout research: Implications for practice and future research. Educational Technology Research and Development, v. 59, n. 5, p. 593-618. 2011.

MORAES, R. Análise de conteúdo. Educação. Porto Alegre: Pontifícia Universidade Católica do Rio Grande do Sul, ano XXII, n. 37, p. 7-31, mar. 1999.

RAMOS, W. M.; BICALHO, R. N. M.; DE SOUSA, J. V. Evasão e persistência em cursos superiores a distância: o estado da arte da literatura internacional. In: ESUD 2014-XI Congresso Brasileiro de Ensino Superior à Distância. p. 1-16. 2014.

REIS, R. S. N.; VELOSO, T. C. M. A. A permanência na educação superior: múltiplos olhares. Educação e Fronteiras On-Line, Dourados-MS, v. 6, n. 6, p. 48-63, 2016.

SACERDOTE, H. C. de S. A mediação segundo Feuerstein e o uso da informação em educação On-Line. 2018. 229 f. Tese (Doutorado) - Curso de Ciência da Informação, Faculdade de Ciência da Informação, Universidade de Brasília, Brasília, 2018.

SILVA FILHO, R. L. L et al. A evasão no ensino superior brasileiro. Cadernos de Pesquisa, v. 37, n. 132, p. 641-659, 2007.

TINTO, V. Dropout from higher education: a theoretical synthesis of recente research. Review of Educational Research, v. 45, n. 1, p. 89-125, 1975.

Recebido em: 30/01/2020

Aprovado: 26/03/2020 